Family Medicine and Community Health

\title{
Implementation of cancer screening in rural primary care practices after joining an accountable care organisation: a multiple case study
}

\author{
Heather Nelson-Brantley (D) ,1,2 Edward F Ellerbeck (D) ,2,3 \\ Stacy McCrea-Robertson, ${ }^{3}$ Jennifer Brull, ${ }^{4}$ Jennifer Bacani McKenney, ${ }^{4}$ \\ K Allen Greiner, ${ }^{2,4}$ Christie Befort ${ }^{2,3}$
}

To cite: Nelson-Brantley $\mathrm{H}$, Ellerbeck EF, McCreaRobertson S, et al. Implementation of cancer screening in rural primary care practices after joining an accountable care organisation: a multiple case study. Fam Med Com Health 2021;9:e001326. doi:10.1136/fmch-2021-001326

- Additional supplemental material is published online only. To view, please visit the journal online (http://dx.doi.org/10. 1136/fmch-2021-001326).

\section{Check for updates}

\section{(c) Author(s) (or their} employer(s)) 2021. Re-use permitted under CC BY-NC. No commercial re-use. See rights and permissions. Published by BMJ.

${ }^{1}$ School of Nursing, University of Kansas Medical Center, Kansas City, Kansas, USA

${ }^{2}$ University of Kansas Cance Center, University of Kansas Medical Center, Kansas City, Kansas, USA

${ }^{3}$ Population Health, University of Kansas Medical Center, Kansas City, Kansas, USA

${ }^{4}$ Family Medicine, University of Kansas Medical Center, Kansas City, Kansas, USA

Correspondence to Dr Heather Nelson-Brantley; hnelson-brantley@kumc.edu

\section{ABSTRACT}

Objective To describe common strategies and practicespecific barriers, adaptations and determinants of cancer screening implementation in eight rural primary care practices in the Midwestern United States after joining an accountable care organisation (ACO).

Design This study used a multiple case study design. Purposive sampling was used to identify a diverse group of practices within the ACO. Data were collected from focus group interviews and workflow mapping. The Consolidated Framework for Implementation Research (CFIR) was used to guide data collection and analysis. Data were crossanalysed by clinic and CFIR domains to identify common themes and practice-specific determinants of cancer screening implementation.

Setting The study included eight rural primary care practices, defined as Rural-Urban Continuum Codes 5-9, in one ACO in the Midwestern United States.

Participants Providers, staff and administrators who worked in the primary care practices participated in focus groups. 28 individuals participated including 10 physicians; one doctor of osteopathic medicine; three advanced practice registered nurses; eight registered nurses, quality assurance and licensed practical nurses; one medical assistant; one care coordination manager; and four administrators.

Results With integration into the ACO, practices adopted four new strategies to support cancer screening: care gap lists, huddle sheets, screening via annual wellness visits and information spread. Cross-case analysis revealed that all practices used both visit-based and populationbased cancer screening strategies, although workflows varied widely across practices. Each of the four strategies was adapted for fit to the local context of the practice. Participants shared that joining the ACO provided a strong external incentive for increasing cancer screening rates. Two predominant determinants of cancer screening success at the clinic level were use of the electronic health record (EHR) and fully engaging nurses in the screening process.

Conclusions Joining an ACO can be a positive driver for increasing cancer screening practices in rural primary care practices. Characteristics of the practice can impact the success of ACO-related cancer screening efforts; engaging nurses to the fullest extent of their education and

\section{Key points}

\section{Question}

- This study examined the unique and collective experiences of eight rural primary care practices to describe common strategies and practice-specific barriers, adaptations and determinants of cancer screening implementation after joining an accountable care organisation (ACO).

\section{Finding}

- Joining the ACO provided important visit-based and population-based cancer screening strategies to increase cancer screening, although workflows varied widely across practices. Two predominant determinants of cancer screening success at the clinic level were use of the electronic health record and fully engaging nurses in the screening process.

\section{Meaning}

- Joining an ACO can be a positive driver for increasing cancer screening in rural primary care practices. Strategies should be adapted for fit into the local context of the practice. Future studies should examine task sharing strategies and adaptations for increasing cancer screening rates in rural primary care practices.

training and integrating cancer screening into the EHR can optimise the cancer screening workflow.

\section{INTRODUCTION}

The benefits of cancer screening have been analysed by the US Preventive Services Task Force, compiled into clinical practice guidelines and incorporated into quality measures for providers and health plans. ${ }^{1-5}$ Nevertheless, rates of cancer screening have fallen short of national objectives. ${ }^{6}$ Rural communities, in particular, face gaps in delivery of evidence-based cancer screening. ${ }^{7-10}$ Rural communities have experienced significantly slower declines in cancer mortality over the 
past, primarily driven by cancers amenable to primary prevention through screening and early detection. ${ }^{11}$

Cancer screening is largely coordinated by primary care providers, but primary care is highly complex and cancer screening activities can be lost amidst the myriad of issues that primary care providers face every day. Multiple studies have examined strategies to improve cancer screening in primary care settings. This research has demonstrated the need for multicomponent interventions, including patient reminders, provider reminders, audit and feedback and efforts to reduce structural barriers to screening. ${ }^{12}$ Electronic health records (EHRs) provide a critical backbone for these multicomponent interventions, including the ability to identify patients who are overdue for screening and provide prompts for patients and providers when screening is due. Primary care practices, however, particularly those in rural communities, may not be well positioned to take advantage of this EHR functionality ${ }^{13} 14$ due to a lack of time, experienced staff or critical data interfaces. ${ }^{14-16}$ Clinical workflows also need to be modified to take full advantage of EHR functionality and often require changes in job duties. Task shifting can offload some of the work traditionally completed by physicians onto other members of the care team to ensure more systematic delivery of services. ${ }^{1718}$

Many primary care practices are now joining ACOs to take advantage of alternative payment models that focus on shared savings and financial incentives for achieving quality targets. Some ACOs have focused specifically on rural or smaller private practices. ${ }^{190}$ By working together as part of an ACO, independent practices can pool resources to improve their infrastructure for information technology, share and disseminate best practices and engage in population health management. ${ }^{20}$ Performancebased payment models provided to ACOs may provide critical organisational incentives to improve performance on preventive services such as cancer screening. Despite these theoretical benefits, it is unclear what common and unique strategies rural practices that join ACOs use to address their specific barriers and successfully integrate cancer screening into their practice. ${ }^{21}$ Thus, the objective of this multiple case study was to describe common strategies and practice-specific barriers, adaptations and determinants of cancer screening implementation in eight rural primary care practices in the Midwestern United States after joining an ACO.

\section{METHODS \\ Design}

This study used a multiple case study design.${ }^{22}{ }^{23}$ Multiple case study is appropriate for closely examining several cases linked together in some way, in our study, the experience of implementing cancer screening practices after joining an ACO. Each case (ie, each rural primary care practice) is a complex entity guided by unique historical, cultural, physical and socioeconomical contexts that are important for understanding the phenomenon of interest. ${ }^{23}$ Multiple case study designs are useful when the aim is to understand the aggregate of cases while also understanding the uniqueness of each case.

\section{Conceptual framework}

This study was guided by the Consolidated Framework for Implementation Research (CFIR) ${ }^{24}$ CFIR postulates that there are multilevel influences on implementation that fall within five primary domains: intervention characteristics, outer setting, inner setting, characteristics of individuals and the implementation process. This study focused on constructs within inner and outer setting domains that were expected to be relevant determinants of cancer screening adoption. Inner setting constructs included structural characteristics such as the general organisation of the clinic, compatibility (ie, cancer screening fit with existing workflows and systems) and goals and feedback such as clear target goals for cancer screening with frequent performance feedback. Outer setting constructs included cosmopolitanism (ie, the degree to which the practice was networked with other practices in the ACO); peer pressure (ie, competitive pressure by other ACO practices) and external policy and incentives (ie, ACO incentives to improve cancer screening performance).

\section{Setting and participants}

The study included a purposive sample of rural primary care practices in one ACO in the Midwestern United States. ${ }^{20}$ The ACO formed in 2016 and has grown to include 29 primary care practices. ${ }^{25}$ The ACO has performance-based contracts with Medicare, Medicaid and several commercial payers, including Medicare Advantage. The ACO is able to aggregate claims data and integrate with different clinic-based EHR platforms to support quality measurement and improvement. Participating practices compare quality indicators on a frequent basis and receive support from practice facilitators to support quality care improvement. ${ }^{25}$ Although these rural practices are linked by their membership in an ACO, the individual practices are geographically separated, and maintain independent ownership and operations. Each practice has its own, separate EHR, distinct hospital affiliations, ownership arrangements and organisational structures. As such, each practice represents a unique case.

Inclusion criteria for this study were rural practices that were: (1) a member of the ACO with an EHR mapped to the ACO's integrated system; (2) classified as rural according to Rural Urban Continuum Codes (RUCC) categories 5-9 and (3) willing to participate in a site visit. The lead clinician at each consenting practice, along with other key clinic staff identified by the clinician as having some level of involvement with cancer screening and the EHR were eligible to participate in focus groups.

\section{Data collection}

Multiple case study designs are most effective when they include $4-10$ cases. ${ }^{23}$ We systematically identified eight practices in the ACO located in geographically distinct 
rural communities (RUCC codes 5-9). Efforts were made to include representation across geographic regions, socioeconomic factors and performance on cancer control measures. The medical director of the ACO contacted potential practices to explore their interest in participating and recruited them for the site visits.

Meetings with staff and key partners from the ACO (ie, medical director, practice transformation specialist and data manager) were held at the outset of the project to discuss goals, priorities and site visit logistics. A global view of data flow at both the ACO and practice level was reviewed. Research staff attended the local ACO Board meeting to observe training on ACO priority topics and interact with practice leaders.

Site visits to eight rural practices were completed from December 2018 through May 2019. A practice transformation specialist from the ACO accompanied research staff on the first two visits. Each visit was comprised of introductions to key practice staff followed by a semistructured focus group interview; in some cases, a brief tour of the practice was conducted.

Data were collected from focus group interviews and workflow mapping. Physicians, nursing staff, office managers and/or quality improvement staff at each clinic participated in an in-person focus group interview, ranging from 3 to 7 individuals per site. The goal was a full description of the case rather than data saturation; therefore, data were collected from all available and willing participants. Focus group sessions were led by two members of the research team (EFE and AG), both male family medicine physicians with experience in focus group facilitation and research. The research project director (SMR) served as a scribe during focus groups to record field notes. Interview questions were guided by inner and outer setting domains of CFIR. Inner setting questions focused on the general organisation of the clinic, breast and colon cancer screening workflows and use of the EHR and staff. Outer setting questions focused on how ACO membership impacted the uptake of evidence-based cancer screening practices. Using Proctor et al criteria, ${ }^{26}$ we identified four core tasks required for cancer screening: (1) identifying patients in need of screening; (2) ordering the screening test, (3) completing the screening and (4) addressing test results. For each of these tasks, we probed on the current strategies used at each clinic, consideration of and barriers to alternative approaches and impact of the ACO. Interview guide is reported in online supplemental table 1. Focus group interviews ranged from 1 to 2 hours and were audio recorded. Because the study entailed evaluation of practice capacity and procedures rather than a study of individuals, the project was determined as exempt by the researchers' Institutional Review Board.

\section{Data analysis}

Inductive qualitative thematic analysis ${ }^{27}$ was used to analyse focus group transcripts and workflow data. Audiorecordings of the focus group interviews were transcribed verbatim and verified for accuracy. Data analysis began with the researchers immersing themselves in the data, reading each interview several times to capture a sense of the whole. ${ }^{28}$ The project manager (SMR) deconstructed the interview transcripts into meaning units, condensed meaning units and codes. Similar codes were grouped into categories through the process of convergence and divergence, leading ultimately to themes. ${ }^{29}$ A qualitative researcher (HNB) with expertise in cross-case analysis then cross-analysed ${ }^{22} 23$ the data to identify common themes and practice-specific contextual barriers, and successful adaptations.

\section{Trustworthiness and methodological rigour}

Trustworthiness and methodological rigour were supported through careful adherence to credibility, dependability, confirmability, transferability and authenticity criteria. ${ }^{30} 31$ The interviewers (EFE and AG) shared openly with the research team their personal interest in the study topic, as family medicine physicians committed to advancing rural primary care. To minimise the possibility of bias in data interpretation and support credibility of the research findings, peer debriefing was conducted with a member of the research team (HN-B) not involved in the focus group interviewing process. Researchers communicated often throughout the coding process to discuss and resolve any differences in coding or interpretation. Member checking occurred at the end of focus group interviews, whereby the interviewer summarised what was discussed and provided opportunity for the participants to verify and clarify. Dependability and confirmability were supported through an audit trail of research activities and field notes. Transferability was supported by a presentation of the data built from thick description and balanced interpretation. Authenticity was supported by the inclusion of multiple rural primary care practices within the ACO.

\section{RESULTS}

\section{Study site characteristics and participant demographics}

Eight rural primary care practices participated in the study (see table 1). The number of commercial and Medicare patients seen by the practice ranged from 829 to 4889 and combined totalled 20606 beneficiaries attributed to the ACO. A total of 28 individuals participated in one of eight focus groups including 11 physicians; three advanced practice registered nurses; eight registered nurses, quality assurance and licensed practical nurses; one medical assistant; one care coordination manager and four administrators.

\section{Themes}

With integration into the ACO, clinics adopted four new strategies to support cancer screening: care gap lists, huddle sheets, screening via annual wellness visits and information spread. 
Table 1 Study site characteristics and participant demographics

\begin{tabular}{|c|c|c|c|c|c|c|}
\hline $\begin{array}{l}\text { Rural practice } \\
\text { site }\end{array}$ & $\begin{array}{l}\text { Ownership/ } \\
\text { designation }\end{array}$ & RUCC & Rural class & $\begin{array}{l}\text { Total no. of } \\
\text { commercial } \\
\text { and Medicare } \\
\text { patients }\end{array}$ & $\begin{array}{l}\text { No. of focus group } \\
\text { participants }\end{array}$ & $\begin{array}{l}\text { Focus group participant } \\
\text { roles }\end{array}$ \\
\hline 2 & Private/RHC & 7 & Small rural & 4889 & 3 & $\begin{array}{l}1 \mathrm{MD}, 1 \mathrm{APRN} \text {, } \\
1 \text { Admin } \\
\text { (Communications } \\
\text { Director) }\end{array}$ \\
\hline 3 & Private & 7 & Small rural & 470 & 3 & $\begin{array}{l}1 \mathrm{DO}, 1 \mathrm{MA} \text {, } \\
1 \text { Admin (Office Manager) }\end{array}$ \\
\hline 4 & Private/RHC & 7 & Small rural & 4089 & 3 & $\begin{array}{l}1 \mathrm{MD}, 1 \mathrm{RN}, \\
1 \mathrm{Admin} \text { (Office Manager) }\end{array}$ \\
\hline 5 & Private/RHC & 5 & Large rural & 3507 & 3 & $3 \mathrm{MDs}$ \\
\hline 8 & Private & 9 & Isolated rural & 1658 & 3 & $\begin{array}{l}1 \mathrm{MD}, 1 \mathrm{APRN}, \\
1 \mathrm{Admin} \text { (Office Manager) }\end{array}$ \\
\hline Total & $\begin{array}{l}4 \text { Private; } \\
3 \text { Private/RHC; } \\
1 \text { Board/FQHC }\end{array}$ & $\begin{array}{l}\text { RUCC } 5=2 \\
\operatorname{RUCC} 7=4 \\
\operatorname{RUCC} 9=2\end{array}$ & $\begin{array}{l}\text { Large }=2 \\
\text { Small }=3 \\
\text { Isolated }=3\end{array}$ & 20606 & 28 & $\begin{array}{l}M D=10 ; \\
D O=1 ; \\
A P R N=3 ; R N / Q A / L P N=8 ; \\
M A=1 ; \\
C C M=1 ; \\
\text { Admin }=4\end{array}$ \\
\hline
\end{tabular}

APRN, advanced practice registered nurse; CCM, care coordination manager; DO, doctor of osteopathic medicine; FQHC, federally qualified health centre; LPN, licensed practical nurse; MA, medical assistant; MD, medical doctor; QA, quality assurance; RHC, rural health centre; RN, registered nurse; RUCC, Rural Urban Continuum Codes.

\section{Care gap lists}

Care gap lists were a population-based reminder system, whereby the ACO routinely provided each practice with a list of patients who were overdue for breast or colorectal cancer screening based on claims and EHR data. An ACO practice facilitator worked with each practice to identify and train a person at the practice on how to use the care gap list. For most practices, the trained practice staff would manually compare the care gap list to the practice EHR and if accurate, practice staff contacted the patient to schedule their cancer screening. Participants shared how care gap list data was important for knowing how the practice was performing and encouraging them to do better. As one participant shared, 'I think one of the biggest things that happened with that and with mammograms was just getting the data and being able to say that no, your rates are terrible, because the more you acknowledge that you think you are doing great you don't actively try to do better' (practice 1, MD).

While all practices reported using care gap lists to identify patients in need of cancer screening, some shared that there were some challenges in the beginning, one explaining, 'Maybe it's partially because we're a rural health clinic and they (ACO administrators) didn't know we couldn't bill for this, and we couldn't do this and that. But we've had to tell them a lot or find things that were wrong with the way they were doing it. So, it's been a collaborative process' (practice 4, MD). Practice staff noted frequent errors in the care gap lists, particularly with colorectal cancer screening. The staff shared how they were able to update the care gap list and provide feedback to the ACO to improve the accuracy of the lists over time.

\section{Huddle sheets}

Huddle sheets were a visit-based reminder system used by practices in this study. Participants explained that the ACO provided practices with a huddle sheet that identified the preventive care services that each patient was due for. The huddle sheet was part of a dashboard system provided by the ACO. Some practices reported using the dashboard provided by the ACO, while others shared how they developed their own form of huddle sheet that was adapted to better meet the needs of that practice. Participants shared that huddle sheets were a new and effective strategy for identifying and ensuring patients receive preventive care, rather than just acute or chronic illness treatment. 'With our chart prep, not only are they prepping for the problem, but they are reviewing the chart for those wellness things, and if they haven't had a mammogram, make a note to discuss that, and if they haven't gotten CRC screening, make a note to discuss that' (practice $3, \mathrm{DO})$. All but one practice in this study used some form of huddle sheet to review patient care needs prior to their scheduled visit. 


\section{Screening via annual wellness visits}

Annual wellness visits for patients 65 years of age and older were prioritised by the ACO as a quality metric for participating rural primary care practices. Participants in this study shared that the structure of the annual wellness visit was helpful in increasing cancer screening for two reasons. First, it required them to review cancer screening recommendations with patients. Second, it provided them with an opportunity to address cancer screening outside the context of addressing acute or chronic health conditions. As one participant explained, 'It's such a big part of what we do, we try to pay attention when they are in for their B/P check or illness, especially those who haven't been in for a while. We say, you know what, those are good things that are part of your wellness visit. We prompt it that way' (practice $3, \mathrm{DO}$ ).

\section{Information spread}

The fourth strategy that practices in this study adopted as a result of joining the ACO was information spread. Participants shared how joining the ACO enabled them to learn from other practices what works well and adapt it to fit their local context. 'I think it is helpful, that is something with our ACO, we steal each other's practices all the time. So, having something that is nice if someone has already invented, I mean you always have to come up with how it fits in your practice' (practice 2, MD). Participants also shared how joining the ACO gave them access to a network of clinics that share information and patient referrals. As one participant explained, 'We have a lot of feedback of people that don't feel like they're siloed. I felt so alone and now I feel like I have a team. They have a drive. We co-refer across the state to each other now' (practice 7, MD).

\section{Cross-case analysis}

Data were cross-analysed ${ }^{22} 23$ by practice to identify common themes and practice-specific contextual barriers, and successful adaptations. Cross-case analysis revealed that all clinics used both visit-based (huddle sheets, wellness visits) and population-based (care gap lists) cancer screening strategies, although workflows varied widely across clinics. Each of the four strategies discussed above was adapted for fit to the local context of the practice.

All the practices were using their EHR to help with screening, but some were able to get the information they needed more easily. Some providers noted that, in order to function, these reminder systems required data on the patient's demographics (ie, gender and age) which was available in the EHR, but also required data on dates of prior screening, which was not always automatically available. About half of the practices had EHRs that were integrated with the providers that performed their breast cancer or colorectal cancer screening services. Above and beyond, some practice's EHRs were sophisticated enough that data could be extracted to easily identify patients who needed or had completed screening. As one participant shared, 'they're pretty good about picking up colonoscopy here, FIT test there, and then when you actually click on the quality tab for colorectal screening, if it's been satisfied, it will actually point to and present the document that supports that' (practice 6, MD). Other practices had developed workarounds in which staff were assigned to manually scan and upload reports and enter data into the EHR. In those instances, the ease with which they could use the data to identify patients in need of screening varied.

Practices also varied by how much they engaged nursing staff and medical assistants in the work of cancer screening. Several providers commented that it was reasonable for a medical assistant to order mammograms, but that colorectal cancer screening required a discussion between the patient and the primary care provider. To address this latter concern, one practice developed a tool for 'informed decision making' for colorectal cancer screening that the nursing staff could review with the patient prior to ordering the test. Six practices allowed the nursing staff to order a mammogram, while two required a primary care provider to place the order. Conversely, for colorectal cancer screening, only two practices allowed nursing staff to place the order, while the other six required this order to be placed by a primary care provider. One physician participant explained why they use nurses in a lot of the cancer screening work stating, 'We learned a long time ago, if you take doctors out of the equation stuff gets done a lot better' (practice $6, \mathrm{MD})$.

\section{Determinants by CFIR domain}

Focus group data were also analysed by CFIR outer and inner setting domains. This analysis yielded important information about determinants of cancer screening implementation. Regarding outer setting, participants shared universally that joining the ACO led to an increased focus on cancer screening. One participant shared that joining the ACO provided a strong external incentive explaining, 'We're much more outgoing with prevention than we used to be before we joined the ACO instead of reactionary whenever someone walks in the door' (practice 1, MD). Another shared how receiving performance data from the ACO created peer pressure to do better, 'It's not just you're doing the job. You have to be doing a better job with everybody else.... the goal could be ninety percent, you're at 91 but your percentile is bad because somebody else is at 92' (practice 5, MD).

The two predominant determinants of cancer screening implementation success in the inner setting domain were use of the EHR and fully engaging nurses. The impact was clearly noted by a participant who explained, 'We were just paper records fouryears ago and so to go from paper records to completely paperless, has been a huge help with their rifle shots (care gap lists) and we really do work those. And the nurses are very involved with that as well' (practice 4, Admin).

While the primary focus of this study was on constructs within the inner and outer setting domains of CFIR, 
two additional constructs emerged during analysis as important determinants of cancer screening adoption: champions and adaptability. Engaging champions in the process emerged as an important determinant of cancer screening implementation. As one participant change champion shared, 'You've got a few who are always hanging back a little bit. That kind of wait, you have to give them a little nudge. And we have a few of those here. But at the same time, we have some champions. Dr. (name) is like that. He is always ready to jump right in. Myself included, let's try this. And we are the ones who figure it out first and make everyone else do it a week or two later' (practice 2, MD)

Finally, adaptability or the ability to adapt cancer screening to fit the local context, was an essential determinant of cancer screening implementation. As one participant shared, 'Every clinic is different, so they (ACO) would come in and they would be like here's what's working for XYZ clinic. Well, we're not XYZ, it looks completely different for us' (practice 4, RN). Practices adapted care gap lists and huddle sheets provided by the ACO to fit within the workflow and/or context of their practice.

\section{DISCUSSION}

Joining an ACO provides incentives for providers to engage in high-value preventive care such as cancer screening through performance feedback on quality metrics and support for system change. ${ }^{32}$ Adoption and implementation of cancer screening is complex, involving structures and processes at the level of both the ACO and the individual practice. Our study identified four key strategies and practice-specific adaptations used by rural primary care practices to improve cancer screening after joining an ACO.

All practices felt the need to adopt multiple strategies to sufficiently address cancer screening. All practices in our study used both population-based and visit-based strategies to improve cancer screening; however, workflows varied widely across practices. These findings further support the strong evidence base for multicomponent interventions to increase cancer screening in rural populations. $^{12}$

Annual wellness visits are a key performance process indicator used by some ACOs for implementing costeffective preventive care including cancer screening, to improve quality measures and promote long-term cost savings. ${ }^{20}$ Processes for universal implementation of annual wellness visits was a relatively new innovation across the eight practices in this study.

EHR utilisation and IT capability varied considerably from practice to practice. We found that ACO data were the most reliable source of population-based screening data for many practices in this study. Very few practices pulled data from their own EHR for population-based review. While many practices had the capacity for pulling these data, the value of the data was hampered by a lack of integration with the providers performing the services; mammograms and colonoscopies were frequently performed by outside providers and in the absence of an electronic interface with these providers meant the health maintenance data was either entered manually or not at all. This limitation to the EHR data within the practice appears to have been a major factor in how populationbased activities were integrated into practice workflows.

Our study illuminated important distinctions among practices in the way they engage nursing staff. Some practices engaged nurses at a high level to prep charts and document actions needed before patients were seen by the provider, while in other practices nursing staff responsibilities were limited to obtaining vital signs and rooming patients. Previous research ${ }^{33}$ demonstrates improved quality care outcomes when nurses are engaged at a higher level in clinical activities as part of the care team. ${ }^{34}$ This approach, commonly referred to as task shifting or task sharing, occurs either as the result of developing a new group of individuals with competencies to perform tasks normally performed by health professionals with more education and training, or through expanding the scope of practice of existing health professionals to take on additional tasks and functions. ${ }^{17}$

Recent research indicates that women living in rural areas are significantly less likely to be adherent to colorectal cancer screening compared with breast cancer screening. ${ }^{35}$ Our findings suggest that engagement of nurses may be one local adaptation that differs across colorectal and breast cancer screening and contributes to a greater rural disparity for colorectal cancer screening. Only two of the eight practices included in our study engaged nursing staff in colorectal cancer screening, compared with six of eight practices that allowed nursing staff to order a mammogram. One practice in our study developed an informed decision-making tool for colorectal cancer screening that shifted the discussion with the patient from the provider to the nurse. Engaging nursing staff at a high level could be an important task sharing strategy for increasing cancer screening practices, particularly those that are complex or time-consuming such as colorectal cancer screening, in rural primary care. Studies that examine this strategy are warranted.

Studies have examined the impact of ACOs on adherence to recommended and non-recommended cancer screening practices with mixed results. For example, The American Urological Association recommends against prostate-specific antigen (PSA) testing for men with a life expectancy of less than 10 years; PSA testing is considered a low-value screening. ACOs are incentivised to decrease low-value wasteful spending, such as PSA testing, yet recent studies indicate that PSA testing rates were not differentially affected by ACO participation, ${ }^{36}$ or were actually higher among ACOs. ${ }^{37}$ High-value cancer screening such as breast cancer was found to be higher among ACO enrollees in one study, ${ }^{37}$ but not in another. ${ }^{38}$ The mixed body of evidence on the impact of ACOs on cancer screening demonstrates the need to examine how 
cancer screening practices are adopted and implemented at the practice level. Our study helps fill this gap.

Our study included a purposive, heterogeneous sample of rural practices that differed by size, rurality, geographic region, socioeconomic factors and performance on cancer control measures. The diverse sample of practices included in our study enabled us to generate an in-depth understanding of how cancer screening is adopted and implemented at the practice level across varying contexts. Importantly, we found adaptability to be a key determinant of cancer screening adoption. A few practices in this study demonstrated high levels of adaptation in terms of changing EHR functions and nurse workflow. Future studies should examine adaptations and information spread of those adaptations.

Primary care practitioners have an important role to play in decreasing cancer screening disparities in rural populations. Implementing preventive cancer screening practices at the practice level can have the biggest impact on patient outcomes. Thus, it is important for practitioners to evaluate their existing workflows. This study identified potentially important strategies for implementing cancer screening through task sharing and integration into the annual wellness visit. Practices joining an ACO should look at the potential opportunities in infrastructure and support for coordination to implement cancer screening at the practice level.

This study has a few notable limitations. First, the study was a multiple case study of eight rural primary care practices. Practices were purposively sampled. As such, findings may not be generalisable to other rural primary care practices. The inclusion of multiple practices with varying levels of rurality and patient case load and cross-case analysis help minimise this limitation. In addition, this study is descriptive in nature only. Thus, correlations between implementation strategy and cancer screening adoption rates are not possible. Future studies using comparative effectiveness hybrid designs to test the effectiveness of different implementation strategies are recommended. Doing so may lead to important advances in the uptake of cancer screening practices in rural primary care and in turn, decrease cancer-related health disparities among rural populations.

\section{CONCLUSION}

Joining an ACO can be a positive driver for increasing the adoption and integration of cancer screening practices into rural primary care. This study illuminated considerable variation in cancer screening workflows across rural primary care practices with common strategies that were adapted to fit the local context of the practice. Characteristics of the practice are important considerations when implementing, and cancer screening should be adapted for fit. Engaging nurses to the fullest extent of their education and training and integrating cancer screening into the EHR can optimise the cancer screening workflow.
Twitter Heather Nelson-Brantley @HNelsonBrantley

Contributors $\mathrm{CB}$ is guarantor of the study. EFE and $\mathrm{CB}$ designed and directed the study. EFE, AG and SM-R recruited clinics and participants and collected the data. $\mathrm{JB}$ and JBMK participated in data collection. $\mathrm{HN}-\mathrm{B}$ and SM-R analysed the data and participated in peer debriefing with EFE and $\mathrm{CB}, \mathrm{JB}$ and JBMK verified data analysis and interpretation of findings. HN-B, EFE, SM-R and CB wrote the manuscript with input from JB, JBMK and AG.

Funding This investigator-initiated research study was funded by the National Cancer Institute of the National Institutes of Health, grant number P30CA168524-07S3.

Disclaimer The study sponsor did not participate in the study design, data collection, analysis or interpretation of the data or preparation or submission of this report.

Competing interests None declared.

Patient consent for publication Not required.

Ethics approval This study was determined as exempt by the Institutional Review Board of the University of Kansas Medical Center.

Provenance and peer review Not commissioned; externally peer reviewed.

Data availability statement № data are available. Not applicable.

Supplemental material This content has been supplied by the author(s). It has not been vetted by BMJ Publishing Group Limited (BMJ) and may not have been peer-reviewed. Any opinions or recommendations discussed are solely those of the author(s) and are not endorsed by BMJ. BMJ disclaims all liability and responsibility arising from any reliance placed on the content. Where the content includes any translated material, BMJ does not warrant the accuracy and reliability of the translations (including but not limited to local regulations, clinical guidelines, terminology, drug names and drug dosages), and is not responsible for any error and/or omissions arising from translation and adaptation or otherwise.

Open access This is an open access article distributed in accordance with the Creative Commons Attribution Non Commercial (CC BY-NC 4.0) license, which permits others to distribute, remix, adapt, build upon this work non-commercially, and license their derivative works on different terms, provided the original work is properly cited, appropriate credit is given, any changes made indicated, and the use is non-commercial. See: http://creativecommons.org/licenses/by-nc/4.0/.

\section{ORCID iDs}

Heather Nelson-Brantley http://orcid.org/0000-0003-2088-7801

Edward F Ellerbeck http://orcid.org/0000-0002-7774-2729

\section{REFERENCES}

1 U.S. Preventive Services Task Force. Recommendation topics. Available: https://www.uspreventiveservicestaskforce.org/uspstf/ recommendation-topics

2 U.S. Preventive Services Task Force. Colorectal cancer: screening, 2021. Available: https://www.uspreventiveservicestaskforce.org/ uspstf/recommendation/colorectal-cancer-screening

3 U.S. Preventive Services Task Force. Breast cancer: screening, 2016. Available: https://www.uspreventiveservicestaskforce.org/uspstf/ recommendation/breast-cancer-screening

4 National Committee for Quality Assurance. HEDIS measures and technical resources, 2020. Available: https://www.ncqa.org/hedis/ measures/

5 Quallity Payment Program. Explore measures \& activities, 2021. Available: https://qpp.cms.gov/mips/explore-measures?tab= qualityMeasures\&py=2021

6 White A, Thompson TD, White MC, et al. Cancer Screening Test Use - United States, 2015. MMWR Morb Mortal Wkly Rep 2017;66:201-6.

7 Doescher MP, Jackson JE. Trends in cervical and breast cancer screening practices among women in rural and urban areas of the United States. J Public Health Manag Pract 2009;15:200-9.

8 Rohatgi KW, Marx CM, Lewis-Thames MW, et al. Urban-Rural disparities in access to low-dose computed tomography lung cancer screening in Missouri and Illinois. Prev Chronic Dis 2020;17:E140.

9 James TM, Greiner KA, Ellerbeck EF, et al. Disparities in colorectal cancer screening: a guideline-based analysis of adherence. Ethn Dis 2006;16:228-33.

10 Cole AM, Jackson JE, Doescher M. Urban-Rural disparities in colorectal cancer screening: cross-sectional analysis of 1998-2005 
data from the centers for disease control's behavioral risk factor surveillance study. Cancer Med 2012;1:350-6.

11 Henley SJ, Jemal A. Rural cancer control: bridging the chasm in geographic health inequity. Cancer Epidemiol Biomarkers Prev 2018;27:1248-51.

12 Community Preventitive Services Task Force. Cancer screening: multicomponent Interventions-Colorectal cancer, 2020. Available: https://www.thecommunityguide.org/findings/cancer-screeningmulticomponent-interventions-colorectal-cancer

13 Krist $\mathrm{AH}$, Beasley JW, Crosson JC, et al. Electronic health record functionality needed to better support primary care. J Am Med Inform Assoc 2014;21:764-71.

14 Carey M, Noble N, Mansfield E, et al. The role of eHealth in optimizing preventive care in the primary care setting. J Med Internet Res 2015;17:e126.

15 Yarnall $\mathrm{KSH}$, Pollak KI, Østbye T, et al. Primary care: is there enough time for prevention? Am J Public Health 2003;93:635-41.

16 Ruhe M, Gotler RS, Goodwin MA, et al. Physician and staff turnover in community primary care practice. J Ambul Care Manage 2004;27:242-8.

17 Deller B, Tripathi V, Stender S, et al. Task shifting in maternal and newborn health care: key components from policy to implementation. Int J Gynaecol Obstet 2015;130 Suppl 2:S25-31.

18 Amin A, Dutta M, Brahmawar Mohan S, et al. Pathways to enable primary healthcare nurses in providing comprehensive primary healthcare to rural, tribal communities in Rajasthan, India. Front Public Health 2020;8:831.

19 Mostashari F, Broome T. The opportunities and challenges of the MSSP ACO program: a report from the field. Am J Manag Care 2016;22:564-8.

20 Powers BW, Mostashari F, Maxson E, et al. Engaging small independent practices in value-based payment: building Aledade's Medicare ACOs. Healthc 2018;6:79-87.

21 Wang H, Gregg A, Qiu F, et al. Breast cancer screening for patients of rural accountable care organization clinics: a multi-level analysis of barriers and facilitators. J Community Health 2018;43:248-58.

22 Yin RK. Case study research: design and methods. 5 edn. Thousand Oaks, CA: SAGE Publications, Inc, 2014.

23 Stake RE. Multiple case study analysis. New York: NY: The Guilford Press, 2006.

24 Damschroder LJ, Aron DC, Keith RE, et al. Fostering implementation of health services research findings into practice: a consolidated framework for advancing implementation science. Implement Sci 2009;4:50.

25 Aledade. Aledade Kansas, 2021. Available: https://www.aledade. com/kansas

26 Proctor EK, Powell BJ, McMillen JC. Implementation strategies: recommendations for specifying and reporting. Implement Sci 2013;8:139.

27 Braun V, Clarke V. Using thematic analysis in psychology. Qual Res Psychol 2006;3:77-101.

28 Elo S, Kyngäs $\mathrm{H}$. The qualitative content analysis process. J Adv Nurs 2008;62:107-15.

29 Patton MQ. Qualitative Research \& Evaluation Methods. 4 edn. Thousand Oaks, CA: SAGE Publications, Inc, 2015.

30 Guba EG, Lincoln YS. Competing Paradigms in Qualitative Research. In: Denzin NK, Lincoln YS, eds. Handbook of qualitative research. Thousand Oaks, CA: SAGE, 1994: 105-17.

31 Lincoln YS, Guba EG. Establishing trustworthiness naturalistic inquiry. Beverly Hills, California: SAGE Publications, Inc, 1985: 289-331.

32 Briggs ADM, Fraze TK, Glick AL, et al. How do accountable care organizations deliver preventive care services? A mixed-methods study. J Gen Intern Med 2019;34:2451-9

33 Pesut B, Hooper B, Jacobsen $\mathrm{M}$, et al. Nurse-Led navigation to provide early palliative care in rural areas: a pilot study. BMC Palliat Care 2017;16:37.

34 Vetter-Smith M, Lemaster J, Olsberg J, et al. Providing diabetes self-management support in rural primary care clinics with nurse partners. West J Nurs Res 2012;34:1023-42.

35 Shete S, Deng Y, Shannon J, et al. Differences in breast and colorectal cancer screening adherence among women residing in urban and rural communities in the United States. JAMA Netw Open 2021;4:e2128000.

36 Luckenbaugh AN, Hollenbeck BK, Kaufman SR, et al. Impact of accountable care organizations on diagnostic testing for prostate cancer. Urology 2018;116:68-75.

37 Meyer CP, Krasnova A, Sammon JD, et al. Accountable care organizations and the use of cancer screening. Prev Med 2017;101:15-17.

38 Cole AP, Krasnova A, Ramaswamy A, et al. Recommended cancer screening in accountable care organizations: trends in colonoscopy and mammography in the Medicare shared savings program. J Oncol Pract 2019;15:e547-59. 